\title{
Predicted impact of lipid lowering therapy on cardiovascular and economic outcomes of Swedish atherosclerotic cardiovascular disease guideline
}

\author{
Gunilla Journath $^{1 *}$ D, Kristina Hambraeus ${ }^{2}$, Emil Hagström ${ }^{3}$, Billie Pettersson ${ }^{4}$ and Mickael Löthgren ${ }^{5}$
}

\begin{abstract}
Background: The effects on cardiovascular disease (CVD) by treatment recommendations on prevention of atherosclerotic CVD remain to be evaluated. The objectives were to assess treatment gap for low density lipoprotein cholesterol (LDL-C) according to guidelines, potential impact on CVD outcomes, and possible avoided economic costs, in post myocardial infarction (MI) patients, if target LDL-C levels of $\leq 1.8 \mathrm{mmol} / \mathrm{L}$ would be achieved.

Methods: All patients registered in the Swedish Secondary Prevention after Heart Intensive care Admission register, with one-year post-MI follow-up during 2013 were selected. The REACH risk prediction and a calibrated model for recurrent cardiovascular events and death were used to estimate unadjusted risk prediction based on the REACH equation henceforth called base case, and calibrated CVD outcomes based on gender-specific risk factors. The predicted impact of the LDL-C reduction on the risk of CVD was based on the Cholesterol Treatment Trialists' Collaboration findings.
\end{abstract}

Results: A sample of $n=5904$ patients (74\% men) with a mean age of 64 years were included. Around $70 \%$ did not reach $L D L-C$ target $\leq 1.8 \mathrm{mmol} / \mathrm{L}$. Over a 10-year period, 820-2262 events were predicted to occur in those who did not reach target corresponding to 20\% - 55\% risk of CVD events. To achieve LDL-C target, the mean LDL-C had to be reduced by $0.73 \mathrm{mmol} / \mathrm{L}$ (29\%). If this LDL-C reduction was achieved, 195-544 life years, 132-343 CVD events, and 7.9-20.9 million Swedish crowns (MSEK) of direct costs, and 19.3-51.0 MSEK of total costs would be avoided.

Conclusion: Lowering of LDL cholesterol to achieve target levels according to guidelines for post-MI patients may lead to fewer cardiovascular events and avoidance of event costs.

Keywords: Cardiovascular disease, Costs, Guidelines, Lipids, Myocardial infarction

\section{Background}

Ischemic heart disease (IHD) is the most common CVD, and the leading cause of death in large parts of the world [1] Reduction of low-density lipoprotein cholesterol (LDL-C) with lipid lowering therapy (LLT) has shown a reduction of the risk of cardiovascular events in both high and low risk individuals [2-4]. Meta-analysis of statin trials observed that further risk reductions were found in patients obtaining LDL-C levels below $1.8 \mathrm{mmol} / \mathrm{L}[5,6]$.

\footnotetext{
* Correspondence: gunilla.journath@ki.se

${ }^{1}$ Cardiology unit, Department of Medicine, Karolinska Institutet, Karolinska

University Hospital, Stockholm, Sweden

Full list of author information is available at the end of the article
}

European guidelines recommend treatment target levels of LDL-C depending on predicted risk for cardiovascular events, with lower target levels for patients at high risk (very high risk: $<1.8 \mathrm{mmol} / \mathrm{L}$; high risk $<2.5 \mathrm{mmol} / \mathrm{L}$; moderate risk $<3 \mathrm{mmol} / \mathrm{L}$ ) [7]. Guidelines from the US have another approach recommending fixed-dose strategies instead of targeted goals to lower blood cholesterol [8]. High intensity statin therapy was recommended for patients with high or very high risk, and a low dose statin therapy to those with moderate risk of cardiovascular disease [8].

The Medical Product Agency in Sweden published treatment recommendations on prevention of atherosclerotic 
cardiovascular disease in 2014 [9], with a similar approach as European guidelines with recommended treatment target of $\mathrm{LDL} \leq 1.8 \mathrm{mmol} / \mathrm{L}$ for high risk patients. Patients with established coronary artery disease were classified as high-risk patients in all CVD prevention guidelines. The risk of recurrent disease remained high despite modern treatment for myocardial infarction [10]. Treatment with lipid-lowering agents is cost-effective, especially in highrisk patients $[11,12]$. To our knowledge the potential consequences the Swedish guideline have not been published.

The aims were to assess treatment gap for LDL-C according to guidelines, potential impact on CVD outcomes, and possible avoided economic costs, in a cohort of Swedish post myocardial infarction (MI) patients, if target LDL-C levels of $\leq 1.8 \mathrm{mmol} / \mathrm{L}$ would be achieved.

\section{Methods}

\section{Setting, study design, and study population}

SWEDEHEART is a Swedish national register in which patients with acute coronary syndrome are prospectively registered. Patient characteristic, hospital treatments, drug treatments at discharge, and outcome for patients consecutively included and treated at all Swedish coronary care units are collected in this register [13]. The Swedish Secondary Prevention after Heart intensive care Admission (SEPHIA) is a sub register within SWEDEHEART collecting data on secondary prevention and cardiac rehabilitation [14]. Follow-up data were registered by office visits or phone call, supplemented by blood samples collected at the patient's primary care centre, at six to ten weeks and at 12 to 14 months post MI. Around $80 \%$ of all Swedish MI patients below the age of 75 years are included in this register [14].

In this study, a cohort of 5904 patients ( $74 \%$ men) registered in the SEPHIA register and who had one year follow-up during 2013, were included. Data from the SWEDEHEART/SEPHIA national register was extracted in an aggregated form. In accordance with Swedish regulations, written informed consent is not necessary for national registers, however all patients were informed about their participation in the register, and their right to decline participation.

\section{Prediction of cardiovascular disease risk}

The Reduction of Atherothrombosis for Continued Health (REACH) risk function was used to predict 20month risk of recurrent CVD [15]. This model provided estimates of recurrent non-fatal and fatal CVD events based on the following risk factors: age (years), gender (male/female), smoking, diabetes mellitus; body mass index (BMI) $<20 \mathrm{~kg} / \mathrm{m}^{2}$, number of vascular beds with CVD-manifestations $(1,2,3)$, congestive heart failure, atrial fibrillation, statin treatment, and acetylsalicylic acid treatment [15]. The predicted 20-month fatal and non-fatal CVD risk were derived from the "next event" $\mathrm{REACH}$ equation using the detailed Cox regression model covariate coefficient estimates provided in Wilson et al. 2012 Appendix [15]. CVD rates were predicted separately for males and females, before calculating a weighted average the overall cohort risk, accounting for gender variation in risk factors. CVD risk was estimated separately for each year in the prediction time period, accounting for the yearly increase in cohort age and the impact of increased age on CVD risk. The predicted 20-months risks were annualized for each year of prediction. The effect on CVD risk derived from the lowering of LDL-C was calculated based on the Cholesterol Treatment Trialists' Collaboration (CTTC) meta-analyses results, linking LDL-C lowering to CVD event risk reduction [6]. Different rate ratios of CVD event reductions per $\mathrm{mmol} / \mathrm{L} \mathrm{LDL}-\mathrm{C}$ reduction were used based on CTTC: MI (0.71), ischemic stroke (IS) (0.69) and fatal CHD (0.80) [6]. For fatal stroke a rate ratio of one was used based on the non-significant difference reported by CTTC [6]. The proportion (\%) of non-fatal (MI and stroke) vs. fatal CVD event post MI, was based on Jernberg et al. reported event distribution of up to 24 months post MI: $46.8 \%$ CVD death, $37.8 \%$ MI, $15.4 \%$ stroke [16]. In the age ranges $55-64$ to $65-74$ years of fatal CHD vs. fatal stroke occurred in $96 \%$ vs. $4 \%$ post$\mathrm{MI}$, indicating that fatal CHD is more common than fatal strokes in post MI patients [17]. The direct costs of nonfatal MI and stroke were based on Hallberg et al. 2015 [18] and were for MI: Swedish crowns (SEK) 76,657, and ischemic stroke: SEK 88,790. These event cost estimates were from Table 4 in Hallberg et al. 2016, and from the incremental cost year (day 0-365 days after new CVD event) for the CVD history cohort. The reported cost estimates were converted to SEK using the same exchange rate of $1 €=8.71$ SEK as reported by Hallberg et al. 2015, p. 3. Fatal CVD costs were estimated, and based on Ara et al. 2009 [19] and were for CHD death costs SEK 11,345 (14.8\% of MI costs) and stroke death SEK 40,577 (45.7\% of stroke costs). Total directs costs of CV events were estimated in a first analysis step. In a second step the total cost including costs of informal care by family and relatives, indirect costs of productivity loss due to premature death, and reduced work capacity ere estimated based on previous findings have shown that direct costs accounted for around $41 \%$ of total costs [20].

The REACH risk prediction model was based on participants from around the world with different prior CVD events, not only MI [19]. Results from the UK Clinical Practice Research Datalink (CPRD) calibration analyses indicated that the REACH risk prediction significantly underestimated the risk of CVD events in a post-acute coronary syndrome population [21]. Analyses of the REACH risk prediction were therefore, calibrated according to CPRD analyses. The CPRD study included 
heart failure (HF) in addition to MI, stroke and CVD mortality outcomes, and hence the reported calibration factor of 3.36 for a post- acute coronary syndrome (ACS) population had to be adjusted for the purpose of this study. Based on the post-ACS cohort, the adjusted calibration factor was $3.06=3.36 *(1-0.089)$ in the CPRD cohort accounting for HF incidence in patients between 64 and 73 years old. In addition to the prediction of fatal and non-fatal CVD event using the REACH risk prediction, the predictions account for Swedish age- and gender specific non-CVD mortality life tables from Statistics Sweden were used (available at www.scb.se/hitta-statistik).

\section{Statistical analyses}

Demographics and other baseline characteristics were presented for the overall study population, as well as for the controlled cohort (LDL-C $\leq 1.8 \mathrm{mmol} / \mathrm{L}$ ), the noncontrolled (LDL-C $>1.8 \mathrm{mmol} / \mathrm{L}$ ) cohort, and in men and women separately. The REACH risk function was used to predict the CVD risk [15], as well as the calibrated CVD risk prediction described above [19]. The possible avoided costs were based on cases at baseline in REACH (henceforth called base case), the calibrated (scenario) risk predictions, the corresponding population's CVD costs and potential cost reductions linked to LDL-C reduction according to guidelines. This was predicted by combining event prediction and estimation of health care costs associated with each type of event.

\section{Results}

Table 1 shows the characteristics of the study population ( $n=5904,74 \%$ men). Around $70 \%$ of the overall cohort did not reach the target of LDL-C $\leq 1.8 \mathrm{mmol} / \mathrm{L}$ (men $69 \%$ and women $75 \%$ ). An average LDL-C reduction of $0.73 \mathrm{mmol} / \mathrm{L}$ (men $0.70 \mathrm{mmol} / \mathrm{L}$, women $0.81 \mathrm{mmol} / \mathrm{L}$ ) was required to achieve the LDL-C target corresponding to an average LDL-C reduction of $29 \%$ (men $28 \%$ and women $31 \%$ ). There was a lower proportion of patients with diabetes, and statin-treated patients, in the noncontrolled group than in the controlled group (Table 1). The base case and calibrated risk predictions ranged from 820 to 2262 total CVD events over a 10-year period in the non-controlled group, corresponding to a baseline CVD event risk of 20\% -55\% (Fig. 1). Over a ten-year period, the LDL-C reductions to reach target was predicted to lead to 195-544 gained life years, 132-343 fewer CVD events (fatal [39-97], non-fatal MI, and stroke [93-246]) (Fig. 2). The corresponding total direct health care costs were predicted to be reduced by 7.9-20.9 (million Swedish crowns) MSEK and total health care costs by 19.3-51.0 MSEK (Fig. 3).

\section{Discussion}

This study shows that around $70 \%$ of very high risk patients with prior MI did not have controlled LDL-C, 12 months post MI. We found that an average additional LDL-C reduction by $29 \%(0.73 \mathrm{mmol} / \mathrm{L})$ would be needed to achieve target level of LDL-C $1.8 \mathrm{mmol} / \mathrm{L}$. This LDL-C reduction was estimated to lead to a total of 132-343 fewer CVD events with corresponding health care costs reduced by in total 19.3-51.0 MSEK, accounting for $20.1 \%$ of the total predicted event costs. Over a ten-year period 805-2262 CVD events was predicted to occur in the non-controlled patients $(n=4145)$,

Table 1 Characteristics of the study population

\begin{tabular}{|c|c|c|c|c|c|c|c|c|c|}
\hline \multirow[t]{2}{*}{ Variable } & \multicolumn{3}{|c|}{ Overall cohort } & \multicolumn{3}{|c|}{$\begin{array}{l}\text { Controlled cohort } \\
\text { (LDL-C } \leq 1.8 \mathrm{mmol} / \mathrm{L})\end{array}$} & \multicolumn{3}{|c|}{$\begin{array}{l}\text { Non-controlled Cohort } \\
(\mathrm{LDL}-\mathrm{C}>1.8 \mathrm{mmol} / \mathrm{L})\end{array}$} \\
\hline & Total & Men & Women & Total & Men & Women & Total & Men & Women \\
\hline n (\%) & $5904(100)$ & $4386(74)$ & $1518(26)$ & $1759(100)$ & $1377(78)$ & $382(22)$ & $4145(100)$ & $3009(73)$ & $1136(27)$ \\
\hline LDL-C, mean (SD) mmol/L & $2.2(0.9)$ & $2.2(0.8)$ & $2.3(0.9)$ & $1.4(0.3)$ & $1.4(0.3)$ & $1.4(0.3)$ & $2.5(0.8)$ & $2.5(0.8)$ & $2.6(0.8)$ \\
\hline \multicolumn{10}{|l|}{ Risk factors for REACH risk predictions } \\
\hline Age, mean (SD) & $64(9)$ & $63(8)$ & $65(9)$ & $64(9)$ & $64(9)$ & $64(9)$ & $64(8)$ & $63(8)$ & $65(8)$ \\
\hline Smoking'(\%) & 13 & 12 & 15 & 13 & 12 & 15 & 13 & 12 & 15 \\
\hline Diabetes mellitus (\%) & 25 & 24 & 27 & 31 & 30 & 34 & 23 & 22 & 25 \\
\hline $\mathrm{BMl}<20 \mathrm{~kg} / \mathrm{m}^{2}(\%)$ & 2 & 1 & 4 & 2 & 1 & 4 & 2 & 1 & 3 \\
\hline Number of vascular beds affected & 1.1 & 1.1 & 1.1 & 1.1 & 1.0 & 1.1 & 1.1 & 1.1 & 1.1 \\
\hline One vascular bed affected (\%) & 95 & 95 & 95 & 95 & 96 & 94 & 95 & 95 & 95 \\
\hline Two vascular beds affected (\%) & 5 & 5 & 5 & 5 & 4 & 6 & 5 & 5 & 5 \\
\hline Congestive heart failure (\%) & 2 & 2 & 2 & 3 & 3 & 3 & 2 & 2 & 2 \\
\hline Atrial fibrillation (\%) & 3 & 3 & 3 & 4 & 4 & 4 & 3 & 3 & 2 \\
\hline Statin treatment (\%) & 92 & 93 & 88 & 99 & 99 & 99 & 89 & 91 & 85 \\
\hline Acetylsalicylic acid treatment (\%) & 92 & 93 & 90 & 93 & 93 & 94 & 92 & 93 & 89 \\
\hline
\end{tabular}




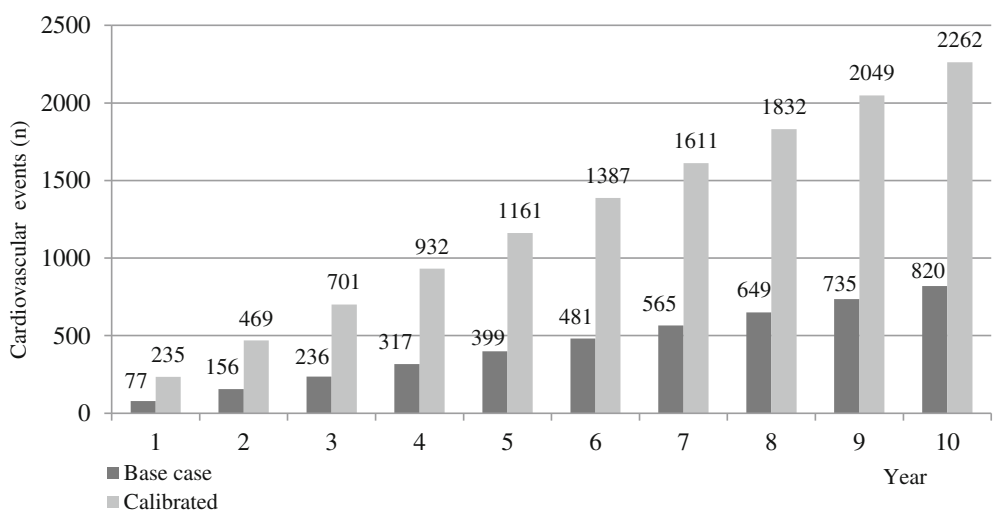

Fig. 1 Predicted number of cardiovascular events in base-, and calibrated cases over a ten year period

corresponding to a $20-55 \%$ ten-year risk of non-fatal MI, stroke and fatal CVD event. A total of 195-544 lives were predicted to be gained over ten years in the study population, if target LDL-levels were achieved.

In the western countries the incidence of MI has declined, and one-year post-MI survival has improved [22, 23]. However, patients who have survived a MI, are still at high risk and one in five was estimated to have a recurrent CVD event during a subsequent 10-year year period [16]. A large proportion of patients in this study received LLT but did not reach LDL-C target according to guidelines [9]. Treatment gaps between guidelines and real world results regarding risk factor control for CHD patients in Europe was reported in the EUROASPIREstudies. Lipid control, defined as LDL $<1.8 \mathrm{mmol} / \mathrm{L}$ increased from 6.1\% in EUROASPIRE II (1999-2000) to 25.6\% in EUROASPIRE IV (2012-2013), revealing a failure of current secondary prevention strategies to deliver best possible treatment to patients after a coronary event [24]. Data from the Swedish quality registry SWEDEHEART showed that goal attainment for LDL-C improved, from $46 \%$ in 2014 to $51 \%$ in 2015 [25]. One explanation for the higher proportion of patients achieving LDL-C goal could be that access to high intensity statins increased, when prices for atorvastatin decreased following the patent expiration. Earlier changes in reimbursement schemes showed that around one fifth of the patients switched from low dose to higher doses of atorvastatin following a new reimbursement scheme, where higher doses of atorvastatin was covered while lower doses were not reimbursed in the new scheme [26]. Non-adherence to prescription may also be a reason for not achieving LDL-C target. Prior observational studies, in patients with IHD, have shown adherence to statin treatment in between $50 \%$ to $79 \%$ [27, 28]. Factors that may affect adherence could be demographic and socioeconomic factors, side effects, life-style, time since last provider visit and number of pills prescribed [29].

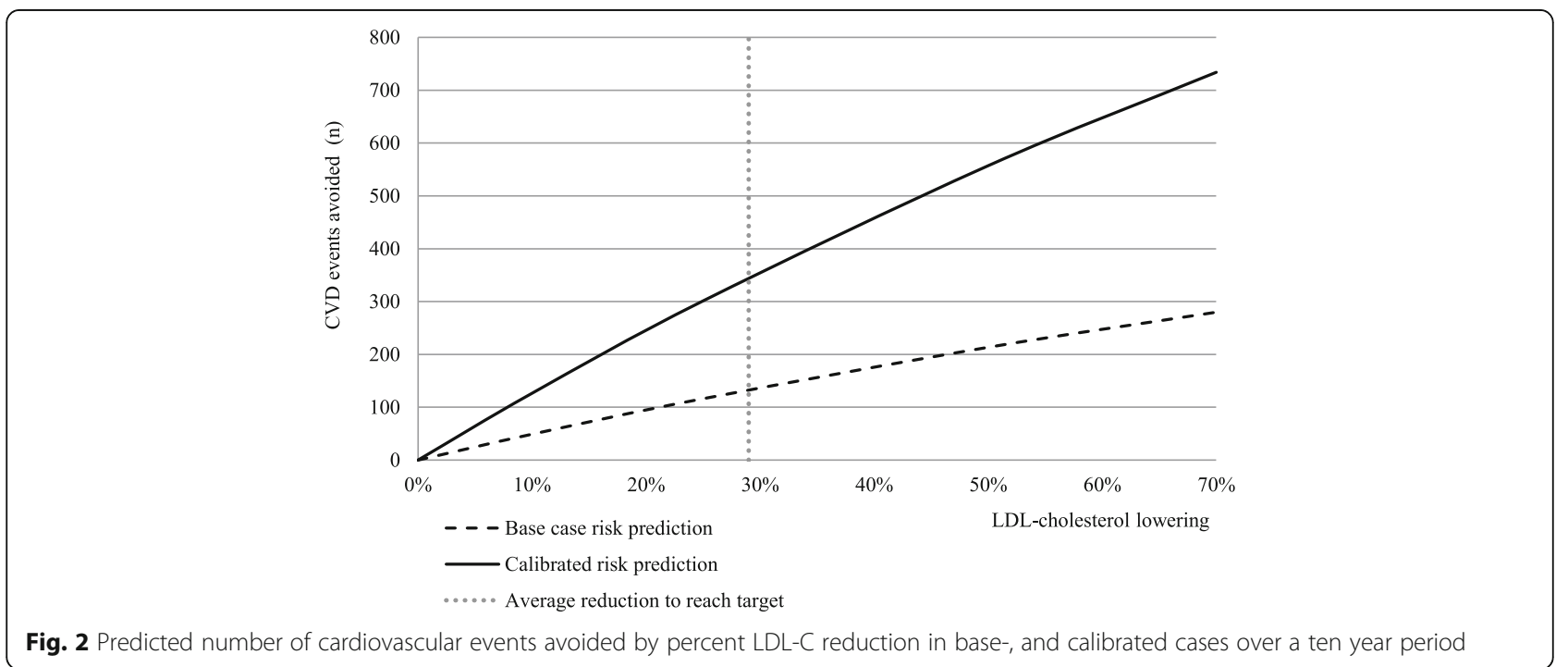




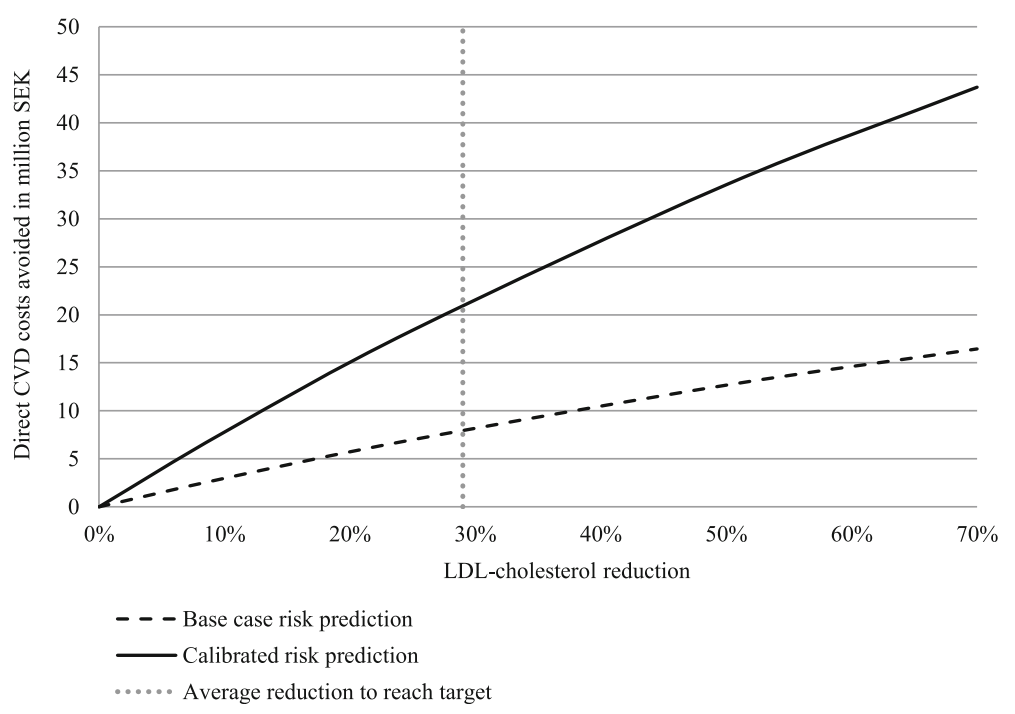

Fig. 3 Predicted direct cardiovascular events costs avoided by percent LDL-C reduction in base-, and calibrated cases

Strategies to improve adherence to secondary prevention medication need to be tailored to relevant patient- and community factors.

The results presented predicted CVD events and costs over a ten-year period for the analysed incident cohort. In order to assess the cost in a given year or over a period of years we needed to assess the CVD events and cost prediction for a prevalent population. This was done based on the available incident cohort and a life time prediction of CVD events and costs underestimated steady-state assumption (ie every year a cohort of same size and characteristics as the study cohorts were assumed to enter post MI). The cohort life-time predictions represented exactly the CVD events and costs expected to materialize in any given year. Under a life-time prediction horizon the base case and calibrated predictions indicated that 1396-2741 life years could be gained, 350-606 CVD events avoided and direct CVD costs reduced 21.4-39.2 MSEK if LDL-C levels were reduced on average $0.78 \mathrm{mmol} / \mathrm{L}$. If willingness to pay for a life year gained is about 553,000 SEK $[30,31]$ then this would mean that the monetary value of the life years gained in our study would be 108-326 MSEK for the estimated 195-544 life-year gained in base case and risk calibrated scenario [30]. In a sensitivity analysis, using an LDL-C lowering up to $70 \%$, up to $280 \mathrm{CVD}$ events could potentially be avoided (vs case 132 events). Up to 19 M SEK due to CVD costs were estimated to be avoided over a 10year period in the cohort. Ongoing outcomes studies with other non-statin therapies as PCSK9-inhibitors will add additional information on whether further lowering of LDL-C will prevent CVD events.

\section{Limitations and strengths}

The presented analyses and results focused on the assessment of the impact on CVD risk and costs if the current LDL-C target was reached in comparison with the current treatment patterns and practices. CVD risk and costs were predicted over a 10-year time horizon accounting for increased age and consequent increased CVD risk over time. However, the analysis was not accounting for any other risk factor changes over time, and is furthermore not accounting for possible future change of statin treatment goal and attainment rate which may change further with physicians' care or disease progression. The post-MI population in this study was younger, due to the age limit of the SEPHIA-register, more often revascularised, and had a higher proportion of men, also due to age inclusion criteria, compared with the MI population in general, which limited the generalizability. Since ICD-10 codes were used for morbidity data there was a possibility for coding errors. However, a validation of the Swedish in patient register showed that coding was concurrent in $>98 \%$ of the cases [32]. The study was based on population averages, and not individual patient-level data. For the analysis of implementation of the guidelines focused on LDL-C this poses some challenges as the guidelines specifies that target LDL-C is $\leq 1.8 \mathrm{mmol} / \mathrm{L}$, or if this cannot be achieved, a $50 \%$ reduction in LDL-C levels. Recently European Guidelines on CVD in clinical practice recommended an LDL-C goal $<1.8 \mathrm{mmol} / \mathrm{L}$, or a reduction of at least $50 \%$ if the baseline is between 1.8 and $3.5 \mathrm{mmol} / \mathrm{L}$ in very high risk patients [33]. The patients in this study represent around $80 \%$ of the total MI-population in Sweden in this age group and, 
potential selection bias was considered to be low. There is a risk of conservative bias, as patients with lower social, financial and health-related functioning may be less likely to attend follow-up visits. The study population should however provide a good estimate of treatment strategies and treatment goals attainment in usual care. Possible future research should compare these risk model based on predictions with actual real-world outcomes over a longer period in the SEPHIA register.

\section{Conclusion}

Despite the multitude of evidence of lowering the CVD risk by intensive secondary prevention there was a large treatment gap between guidelines and achievement of target LDL-C. Lowering of LDL cholesterol to achieve target levels according to guidelines for post-MI patients may lead to fewer cardiovascular events and avoidance of event costs.

\section{Abbreviations}

ACS: Acute coronary syndrome; CHD: Coronary heart disease; CPRD: The UK Clinical Practice Research Datalink; CTTC: The Cholesterol Treatment Trialists' Collaboration; CVD: Cardiovascular disease; EUROASPIRE: European Society of Cardiology survey of secondary prevention of coronary heart disease; HF: Heart failure; IHD: Ichemic heart disease; LDL-C: Low density lipoprotein cholesterol; LLT: Lipid lowering theraphy; MI: Myocardial infarction; MSEK: Million Swedish crowns; REACH: The Reduction of Atherotrombosis for Continued Health; SEK: Swedish crowns; SEPHIA: The Swedish Secondary Prevention after Heart intensive care Admission Swedeheart: Swedish quality registers of coronary heart diseases; US: United States

\section{Acknowledgements}

We thank all participating centers in the SWEDEHEART register that collected the data, and Professor Johan Sundström, Uppsala Clinical Research Center, and Department of Medical Sciences, Uppsala University, Sweden, for valuable support during the planning of the study.

\section{Funding}

Amgen $A B$ supported the study financially by paying the costs for extraction of data registers, and administration.

\section{Availability of data and materials}

The data that support our study are available in the SWEDEHEART register but are not publicly available [34].

\section{Authors' contributions}

$\mathrm{BP}, \mathrm{GJ}, \mathrm{KH}, \mathrm{EH}$, and $\mathrm{ML}$ made substantial contributions to the conception, and design. $\mathrm{KH}$, and EH contributed with acquisition of data. The manuscript was drafted by GJ and ML. ML and BP were responsible for the data analyses. All authors critically reviewed drafts of the manuscript, were responsible for the interpretation of the findings, and approved the final version of the manuscript.

\section{Ethics approval and consent to participate}

According to the Swedish Patient Data Act (2008:355), it is not necessary for persons participating in registers to submit written consents. They are informed that the registration will take place, and may refuse it. The study protocol was approved by the Regional Ethical Review Board in Stockholm (reference number 2015/4:7).

\section{Consent for publication}

Not applicable.

\section{Competing interests}

Financial disclosures: GJ has received consultant fee from Amgen. KH has received lecture fees from Amgen, and Astra Zeneca, and an unrestricted grant from Gilead Inc. EH is an expert committee member, and have received lecture fees, and institutional research grant from Sanofi; institutional research grant and lecture fees from Amgen; institutional research grants from AstraZeneca; expert committee member for Ariad and MSD. BP and ML are employed by Amgen.

\section{Publisher's Note}

Springer Nature remains neutral with regard to jurisdictional claims in published maps and institutional affiliations.

\section{Author details}

${ }^{1}$ Cardiology unit, Department of Medicine, Karolinska Institutet, Karolinska University Hospital, Stockholm, Sweden. ${ }^{2}$ Department of Cardiology, Falun Hospital, Falun, Sweden. ${ }^{3}$ Uppsala Clinical Research Center, and Department of Medical Sciences, Uppsala University, Uppsala, Sweden. ${ }^{4}$ Amgen Inc, Thousand Oaks, California, USA. ${ }^{5}$ Amgen (Europe) GmbH, Zug, Switzerland.

Received: 21 April 2017 Accepted: 7 August 2017

Published online: 16 August 2017

\section{References}

1. Mathers $C D$, Loncar D. Projections of global mortality, and burden of disease from 2002 to 2030. PLoS Med. 2006;3:e442.

2. Bjorck L, Rosengren A, Bennett K, Lappas G, Capewell S. Modelling the decreasing coronary heart disease mortality in Sweden between 1986 and 2002. Eur Heart J. 2009:30:1046-56.

3. Cholesterol Treatment Trialists CTT, Mihaylova B, Emberson J, et al. The effects of lowering $L D L$ cholesterol with statin therapy in people at low risk of vascular disease: meta-analysis of individual data from 27 randomised trials. Lancet. 2012;380:581-90.

4. Zoungas S, Curtis AJ, MCNeil JJ, Tonkin AM. Treatment of dyslipidemia and cardiovascular outcomes: the journey so far-is this the end for statins? Clin Pharmacol Ther. 2014;96:192-205.

5. Boekholdt SM, Arsenault BJ, Hovingh GK, et al. Levels and changes of HDL cholesterol and apolipoprotein A-l in relation to risk of cardiovascular events among statin-treated patients: a meta-analysis. Circulation. 2013;128:1504-12.

6. Cholesterol Treatment Trialists CTT, Baigent C, Blackwell L, et al. Efficacy and safety of more intensive lowering of LDL cholesterol: a meta-analysis of data from 170,000 participants in 26 randomised trials. Lancet. 2010;376:1670-81.

7. Perk J, De Backer G, Gohlke H, et al. European guidelines on cardiovascular disease prevention in clinical practice (version 2012): the fifth joint task force of the European Society of Cardiology and Other Societies on cardiovascular disease prevention in clinical practice (constituted by representatives of nine societies and by invited experts). Eur Heart J. 2012;33:1635-701.

8. Stone NJ, Robinson JG, Lichtenstein AH, et al. 2013 ACC/AHA guideline on the treatment of blood cholesterol to reduce atherosclerotic cardiovascular risk in adults: a report of the American College of Cardiology/American Heart Association task force on practice guidelines. Circulation. 2014;129:S1-45.

9. Medical product Agency. To prevent atherosclerotic cardiovascular disease with drugs- treatment recommendation. https://lakemedelsverket.se/ upload/om-lakemedelsverket/publikationer/informationfranlakemedelsverket/2014/Information_fran_lakemedelsverket_nr_5_2014_ webb.pdf. Accessed 16 Oct 2016.

10. Fox KA, Carruthers KF, Dunbar DR, et al. Underestimated and under-recognized: the late consequences of acute coronary syndrome (GRACE UK-Belgian study). Eur Heart J. 2010;31:2755-64.

11. Lindgren P, Graff J, Olsson AG, Pedersen TJ, Jonsson B, Investigators IT. Cost-effectiveness of high-dose atorvastatin compared with regular dose simvastatin. Eur Heart J. 2007:28:1448-53.

12. Gandhi SK, Jensen MM, Fox KM, Smolen L, Olsson AG, Paulsson T. Costeffectiveness of rosuvastatin in comparison with generic atorvastatin and simvastatin in a Swedish population at high risk of cardiovascular events. ClinicoEconomics and outcomes research: CEOR. 2012;4:1-11.

13. Jernberg T, Attebring MF, Hambraeus K, et al. The Swedish web-system for enhancement and development of evidence-based care in heart disease evaluated according to recommended therapies (SWEDEHEART). Heart. 2010;96:1617-21.

14. SWEDEHEART (2014). Annual report 2013. http://www.ucr.uu.se/swedeheart/. Accessed 16 Oct 2016.

15. Wilson PW, D'Agostino R Sr, Bhatt DL, et al. An international model to predict recurrent cardiovascular disease. Am J Med. 2012;125:695-703. 
16. Jernberg T, Hasvold P, Henriksson M, Hjelm H, Thuresson M, Janzon M. Cardiovascular risk in post-myocardial infarction patients: nationwide real world data demonstrate the importance of a long-term perspective. Eur Heart J. 2015:36:1163-70.

17. Ara R, Tumur I, Pandor A, et al. Ezetimibe for the treatment of hypercholesterolaemia: a systematic review and economic evaluation. Health Technol Assess. 2008;12:21.

18. Hallberg S, Gandra SR, Fox KM, et al. Healthcare costs associated with cardiovascular events in patients with hyperlipidemia or prior cardiovascular events: estimates from Swedish population-based register data. Eur J Health Econ. 2015; doi:10.1007/s10198-015-0702-0.

19. Ara R, Pandor A, Stevens J, Rees A, Rafia R. Early high-dose lipid-lowering therapy to avoid cardiac events: a systematic review and economic evaluation. Health Technol Assess. 2009;13:1-74. 5-118

20. Steen-Karlsson K, and Persson U. (2012) Kostnader för Hjärt-Kärlsjukdom år 2010 IHE Rapport Lund: Institutet för Hälso- och Sjukvårdsekonomi.

21. Danese M LM, Villa G, Lindgren P, van Hout B, and Taylor B. Differences between observed and predicted cardiovascular event rates using standard tools for risk prediction. The case of high-intensity statin users in the United Kingdom. Circulation 2015; 132: A18114 2015.

22. Nichols M, Townsend N, Scarborough P, Rayner M. Trends in age-specific coronary heart disease mortality in the European Union over three decades: 1980-2009. Eur Heart J. 2013;34:3017-27.

23. Nichols M, Townsend N, Scarborough P, Rayner M. Cardiovascular disease in Europe: epidemiological update. Eur Heart J. 2013;34:3028-34.

24. Kotseva K, Wood D, De Bacquer D, et al. EUROASPIRE IV: a European Society of Cardiology survey on the lifestyle, risk factor and therapeutic management of coronary patients from 24 European countries. Eur J Prev Cardiol. 2016;23:636-48.

25. SWEDEHEART (2017). Annual report 2016. http://www.ucr.uu.se/swedeheart/ dokument-sh/arsrapporter. Accessed 2 March 2017.

26. Pettersson B, Hoffmann M, Wandell $P$, Levin LA. Utilization and costs of lipid modifying therapies following health technology assessment for the new reimbursement scheme in Sweden. Health policy. 2012;104:84-91.

27. Foody JM, Joyce AT, Rudolph AE, Liu LZ, Benner JS. Persistence of atorvastatin and simvastatin among patients with and without prior cardiovascular diseases: a US managed care study. Curr Med Res Opin. 2008;24:1987-2000.

28. Ho PM, Spertus JA, Masoudi FA, et al. Impact of medication therapy discontinuation on mortality after myocardial infarction. Arch Intern Med. 2006;166:1842-7.

29. Ho PM, Bryson CL, Rumsfeld JS. Medication adherence: its importance in cardiovascular outcomes. Circulation. 2009;119:3028-35.

30. Persson U, Norinder A, Hjalte K, Gralen K. The value of a statistical life in transport: findings from a new contingent valuation study in Sweden. J Risk Uncertainty. 2001;23:121-34.

31. Persson U, Hjelmgren J. Health services need knowledge of how the public values health. Lakartidningen. 2003;100(43):3436-7.

32. Ludvigsson JF, Andersson E, Ekbom A, et al. External review and validation of the Swedish national inpatient register. BMC Public Health. 2011;11:450.

33. Piepoli MF, Hoes AW, Agewall S, et al. 2016 European guidelines on cardiovascular disease prevention in clinical practice: the sixth joint task force of the European Society of Cardiology and Other Societies on cardiovascular disease prevention in clinical practice (constituted by representatives of 10 societies and by invited experts): developed with the special contribution of the European Association for Cardiovascular Prevention \& rehabilitation (EACPR). Eur Heart J. 2016;37:2315-81.

34. SWEDEHEART. http://www.ucr.uu.se/swedeheart/. Accessed 3 August 2017.

\section{Submit your next manuscript to BioMed Central and we will help you at every step:}

- We accept pre-submission inquiries

- Our selector tool helps you to find the most relevant journal

- We provide round the clock customer support

- Convenient online submission

- Thorough peer review

- Inclusion in PubMed and all major indexing services

- Maximum visibility for your research

Submit your manuscript at www.biomedcentral.com/submit
Biomed Central 